\title{
A Research on Niw Alloy Coatings on Mild Steel through Electrodeposition Method
}

\author{
R. Kannan, K. Sankar, K. Venkatesh, P. Sathyabalan
}

\begin{abstract}
In order to enhance the structural and mechanical properties of mild steel, NiW nanocrystalline thin layer has been coated on the surface of mild steel through electroplating technique at bath temperature of $40^{\circ} \mathrm{C}$ over the deposition time of 45 minutes. The nanocrystalline $\mathrm{NiW}$ alloy coatings were deposited on mild steel at constant current density of $1 \mathrm{~A} / \mathrm{dm}^{2}$. The structural and chemical characterizations of the NiW alloy coated mild steel were performed by scanning electron microscopy (SEM) and X-ray diffraction pattern (XRD). The micro hardness value of the coated mild steel was determined by using Vickers Hardness test. The effect of $\mathrm{NiW}$ on wear behavior of mild steel was analyzed using Pin-on-disc apparatus. The mechanical properties of mild steel such as hardness, roughness and wear resistance have been enhanced in an appreciable manner. This is primarily due to the NiW alloy coatings on mild steel. The variations in structural and mechanical properties of NiW coated mild steel were also studied.
\end{abstract}

Keywords - Mild steel, NiW, hardness, roughness and wear.

\section{INTRODUCTION}

Mild Steel is a metal containing a small percentage of carbon which is also known for plain carbon steel or lowcarbon steel. Mild steel has approximately 0.05 to $0.25 \%$ range of carbon content. Mild steel plays a remarkable role in automobile and electrochemical industries due to its cost effective and excellent mechanical properties like high strength, weldability. Due to the weldability of mild steel, it can be used as a construction materials. The industrial usage and domestic usage of the mild steel is much higher as compared to other form of steel because of its availability and relatively lower price [1-4]. In developing industrial revolution, the advancement of material plays a vital role. In many of the manufacturing industries, mild steel act as a best raw material for the production of machine components like gears. Production of new alloy material gives much improved properties of existing material [5]. The above reason pave a way for coating, which help to improve or increase the wear resistance and hardness of coated material. In order to enhance the mechanical properties of mild steel, thin alloy coatings were preferred. There are several physical and chemical methods are available to coat the thin layers on mild steel [6-10]. In the present research work, electroplating have been chosen for the coating purposes due to its several advantages. Coating can be done by electro deposition because of its specific features like thickness

Revised Manuscript Received on July 18, 2019.

R. Kannan, Department of Science and Humanities - Physics Division, Kumaraguru College of Technology, Coimbatore - 49, Tamilnadu, India. (E-mail: kannan.r.sci@kct.ac.in)

K. Sankar, Department of Mechanical Engineering Kumaraguru College of Technology, Coimbatore - 49, Tamilnadu, India.

K. Venkatesh, Department of Mechanical Engineering Kumaraguru College of Technology, Coimbatore - 49, Tamilnadu, India.

P. Sathyabalan, Department of Mechanical Engineering Kumaraguru College of Technology, Coimbatore - 49, Tamilnadu, India. control and morphology of nanostructure can be obtained precisely by altering the parameters of the electrochemical deposition [11-14].The additional advantage of this type is cost effective compared to other method and no vacuum is requirement. Nano structured thin layer coatings on mild steel is to create the remarkable production for mild steel against corrosion. In the recent days, the researchers show much interest on nano layer coatings to enhance the mechanical properties of base materials like mild steel, copper and aluminium. The nano coatings of $\mathrm{W}$ enhances the wear resistance and hardness of mild steel due to its excellent properties like high strength, high melting point, better corrosion resistance etc., Among various metals, zinc, chromium, titanium and their corresponding alloys have been coated on mild steel to enhance its structural and mechanical properties and are reported [15-16]. The current research work mainly investigate the effect of NiW alloy coatings on the structural and mechanical properties of mild steel for automobile and mechanical high strength applications.

\section{EXPERIMENT}

The nano structured NiW alloy thin layer coatings are coated on the surface of mild steel at bath temperature of $40^{\circ} \mathrm{C}$ over the deposition time of 45 minutes through electroplating technique. The electroplating bath details like concentration, $\mathrm{pH}$ and temperature are shown in table 1 . The mild steel plate of size $7.5 \mathrm{~cm}$ as length and $1.5 \mathrm{~cm}$ as breadth have been used as a cathode and a pure mild steel of above said size act as an anode. In order to enhance the quality of thin layer coatings, just before the deposition both the substrates were subjected to the sequences of cleaning processes. Initially the substrates have been cleaned with help of emery sheets and followed by soap, acid (diluted $\mathrm{H}_{2} \mathrm{So}_{4}$ ) cleaning. Finally all the substrates are washed by using triple distilled water. All the required chemicals were dissolved in triple distilled water to make the electrolytic bath for NiW alloy coatings. The polished substrates were dipped into the prepared electrolytic bath. The $\mathrm{pH}$ of the solution was kept in range between 7 to 8 by adding few drops of liquid ammonia. The constant current of $75 \mathrm{~mA}$ was allowed to pass through the substrates with help of dual power supply. After 45 minutes the cathode was carefully removed from electroplating bath and washed by distilled water. The NiW coated mild steel was dried for few seconds and packed with the help of air lock covers. 
To explore the structural and mechanical properties of $\mathrm{NiW}$ coated mild steel, all the coted mild steels were subjected to various characterization methods like SEM (Scanning Electron Microscope), XRD (X-ray diffraction pattern) and wear analysis.

Table 1.Electroplating bath details for NiW thin layers

\begin{tabular}{|l|l|l|}
\hline S.No & Chemical / Parameter & Data $(\mathbf{g} / \mathbf{l})$ \\
\hline 1 & Nickel sulphate & 50 \\
\hline 2 & Sodium Tungstate & 15 \\
\hline 3 & Tri sodium citrate & 50 \\
\hline 4 & Boric acid & 10 \\
\hline 5 & Bath temperature & $40{ }^{\circ} \mathrm{C}$ \\
\hline 6 & Current density & $150 \mathrm{~mA} / \mathrm{cm}^{2}$ \\
\hline 7 & Plating Time & $45 \mathrm{mins}$ \\
\hline
\end{tabular}

After the NiW thin layer synthesis process on mild steel, the weight of the substrate was note and compared with initial weight of mild steel. The difference between weights of mild steel befor and after coating is the amont of NiW coated on the mild steel surface.

\section{RESULT AND DISCUSSION}

\section{A. Structural analysis}

The microstructural analysis of $\mathrm{NiW}$ coated thin film was shown in figure 1 . The SEM micrograph reveals that the $\mathrm{NiW}$ coated area of mild steel is bright, uniform, void free and almost crack free. The $\mathrm{Ni}$ and $\mathrm{W}$ atoms were uniformly distributed over the surface of mild steel.

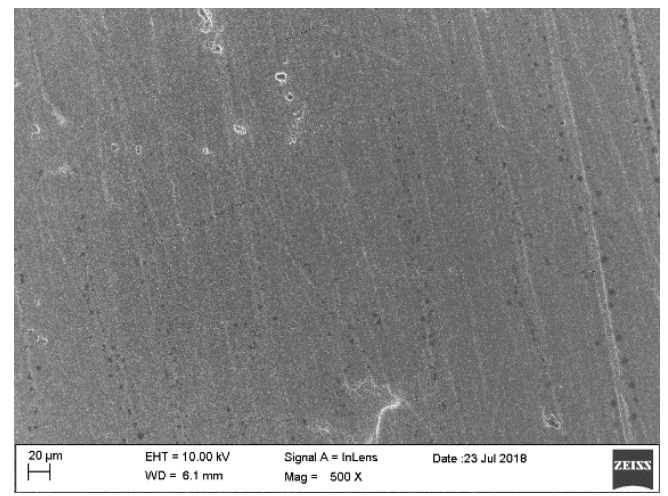

Figure 1. SEM micrograph of NiW thin layer coated mild steel

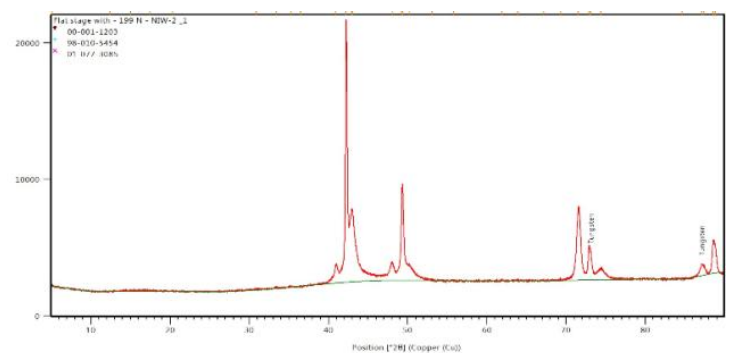

Figure 2. XRD pattern of NiW coated mild steel.

The X-ray diffraction pattern of NiW thin layer coated on mild steel surface is shown in figure 2. The XRD result reveals the presence of crystalline phase in NiW thin layer. The obtained data were compared with standard JCPDS and found that the crystal structure was cubic. The crystalline size was calculated by using Scherrer formula. From XRD data, it is concluded that the average crystalline size is around $83 \mathrm{~nm}$. The presence of perfect nano level in NiW thin layers on mild steel greatly enhances the mechanical properties of mild steel like high hardness, better corrosion resistance and enhanced wear resistance. The $\mathrm{d}$ - spacing value in NiW alloy is found to be $1.58 \AA$.

\section{B. Wear analysis}

The MS (mild steel) plate coated with nanocrystalline $\mathrm{NiW}$ thin film is subjected to uni-directional wear analysis using Pin on disc apparatus. A steel disc (10 cm diameter) of hardness $72 \mathrm{HRC}$ is used for the test. The wear test results are obtained after a time period of 6.3 minutes (time taken for wear test). Wear, coefficient of friction, frictional force are recorded online during the test against the time. The obtained wear results of NiW coated mild steel and uncoated mild steel are shown in the figure 3 and 4 . The graph is plotted between wear vs time, coefficient of friction vs time and Frictional force vs time.

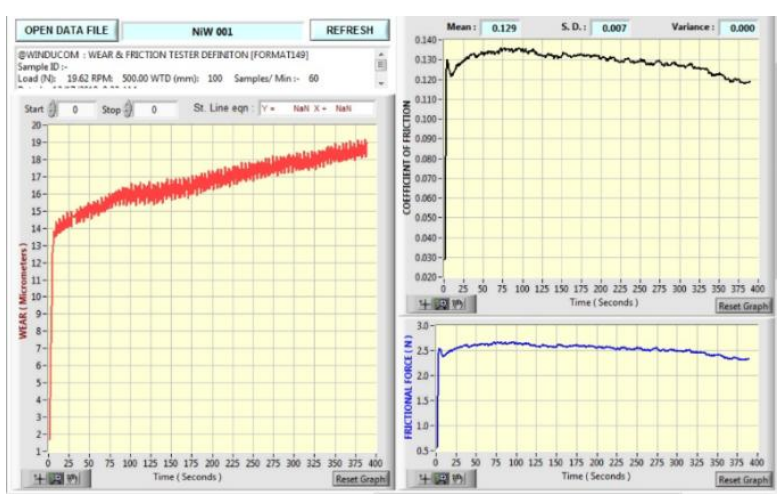

Figure 3: Wear analysis of NiW coated mild steel.

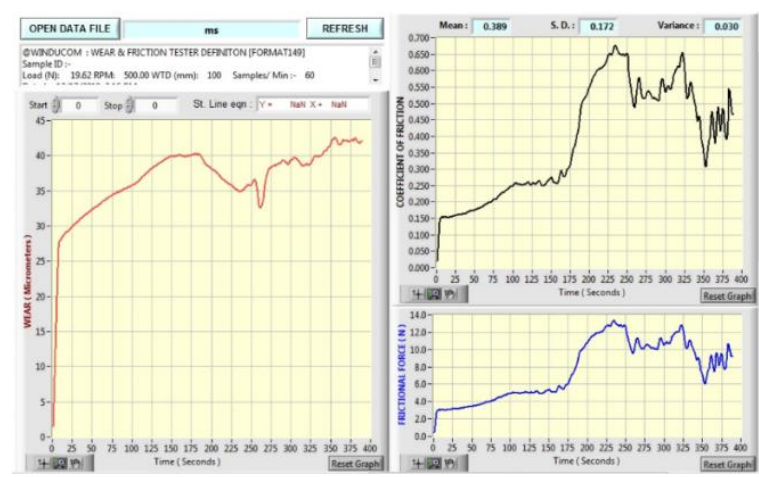

Figure 4: Wear analysis of uncoated mild steel.

The wear tests were carried out for a total sliding distance of $100 \mathrm{~mm}$. The pin samples were rectangular specimen of length $6 \mathrm{~cm}$. From the obtained results, the coefficient of friction of MS sample and Ni-W thin layer sample against time are compared in the figure 5. From the graph, it is seen that coefficient of friction for both MS \& NiW thin layer initially increases suddenly but after this sudden slope, coefficient of friction of MS sample varies non-linearly \& reaches a maximum value as 0.67 , whereas the $\mathrm{NiW}$ thin layer maintains its maximum value as 0.13 and remains same throughout the test.

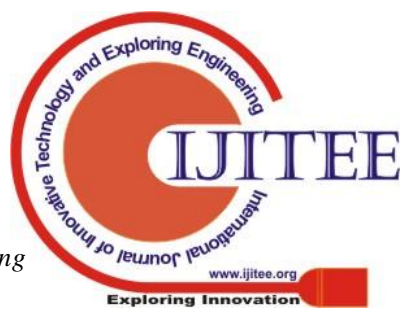




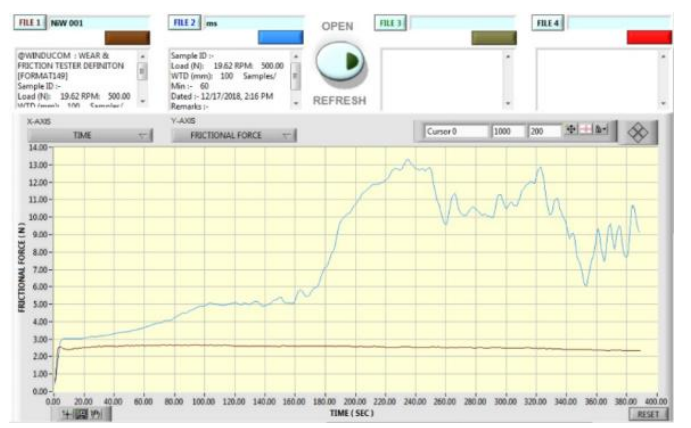

Figure 5: Comparison of time vs coefficient of friction for MS (blue) and NiW coated MS (brown)

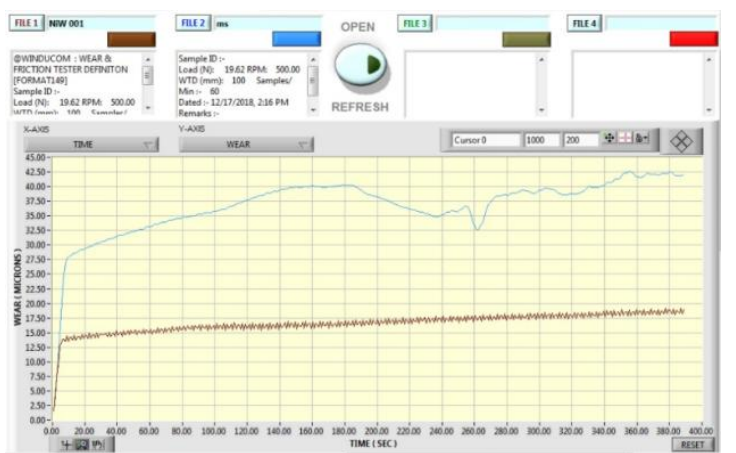

Figure 6: Comparison of time vs frictional force for MS (blue) and NiW coated MS (brown)

Table 2: The constant parameters of pin-on-disc experiment

\begin{tabular}{|l|l|}
\hline Name of parameters & Data \\
\hline \multirow{3}{*}{ Pin material } & Sample1: Mild steel \\
\cline { 2 - 2 } & $\begin{array}{l}\text { Sample2: NiW coated } \\
\text { mild steel }\left(40^{\circ} \mathrm{C}\right)\end{array}$ \\
\hline Disc material & EN 31 steel \\
\hline Load & $20 \mathrm{~N} / 2 \mathrm{kgf}$ \\
\hline Linear sliding distance & $1000 \mathrm{~m}$ \\
\hline Rotational speed & $500 \mathrm{rpm}$ \\
\hline
\end{tabular}

Thus from these observations, NiW thin layer helps to drastically decrease the coefficient of friction value of the mild steel. The frictional force of MS sample and Ni-W thin layer sample against time are compared in the figure 6. It is seen that the initial frictional force acting on both MS \& $\mathrm{NiW}$ thin layer produce very steep slope against time. The pin and disc experimental details are shown in table 2 and the calculated value of wear analysis are shown in table 3.similar to the coefficient of friction, the frictional force on MS increases non-linearly \& reaches a maximum value of $13.3 \mathrm{~N}$, when the test is done with application of $20 \mathrm{~N}$ load, whereas the maximum frictional force acting on the NiW thin layer is around $2.5 \mathrm{~N}$, when the test is done with application of $20 \mathrm{~N}$ load. The drastic reduction in frictional force between MS \& NiW samples is due to decrease of coefficient of friction of NiW thin layer.

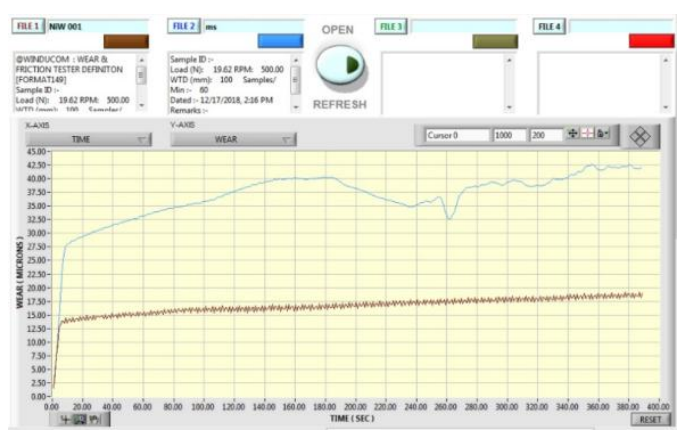

Figure 7: comparison of time vs wear for MS (blue) and NiW coated MS (brown)

The wear of MS sample and NiW thin layer sample against time are compared from the figure 7 . It is seen that the wear resistance of mild steel is increased nearly twice when it is coated with NiW thin layer and also the shows figure 7hat, for both MS \& NiW thin layer, the initial time vs wear slope is inclined nearly to the vertical line which infers that the initial wear rate is higher and then get gradually decreased and maintained along the time. The final wear value of MS sample is around $41 \mu \mathrm{m}$ which is decreased to $19 \mu \mathrm{m}$ for $\mathrm{NiW}$ thin layer.

Table 3: Wear loss, frictional force and coefficient of friction of MS and NiW coated MS

\begin{tabular}{|l|l|l|l|c|}
\hline Sample & $\begin{array}{l}\text { Wear } \\
\text { loss } \\
(\boldsymbol{\mu m})\end{array}$ & $\begin{array}{l}\text { Friction } \\
\text { al force } \\
(\mathbf{N})\end{array}$ & $\begin{array}{l}\text { Coeffici } \\
\text { ent of } \\
\text { friction }\end{array}$ & $\begin{array}{c}\text { Wear Rate } \\
\left(\begin{array}{c}\mathbf{1 0}_{\mathbf{- 5}}^{\mathbf{3}} \mathbf{\mathbf { m }} \mathbf{- 1} \\
\mathbf{\mathbf { m }}\end{array}\right.\end{array}$ \\
\hline $\begin{array}{l}\text { Mild } \\
\text { steel }\end{array}$ & 41 & 9.1 & 0.47 & 5.976 \\
\hline $\begin{array}{l}\text { NiW } \\
\text { coated } \\
\text { MS }\end{array}$ & 19 & 2.42 & 0.14 & 2.686 \\
\hline
\end{tabular}

From the table 3, the wear rate of the uncoated mild steel is high and the NiW coated mild steel exhibit lower wear rate. Thus, it is evidenced that the wear resistance of $\mathrm{NiW}$ coated mild steel at $40{ }^{\circ} \mathrm{C}$ has the better wear resistance.

\section{CONCLUSION}

In this present investigation, nano crystalline $\mathrm{NiW}$ thin layer has been successfully coated on the mild steel surface for high strength applications through electroplating technique. The observed details are listed below.

* From SEM analysis it is concluded that, the NiW coated thin mild steel surface is uniform, bright, crack free and void free.

* The XRD pattern of NiW coated mild steel exhibit the nanocrystalline phase and the average crystalline size was calculated as around $83 \mathrm{~nm}$.

* The wear analysis of coated and uncoated mild steel have been compared by using pin and disc method.

* From the comparison of coated and uncoated MS samples it is seen that the wear of MS rod is reduced nearly twice when it is coated with NiW alloy.

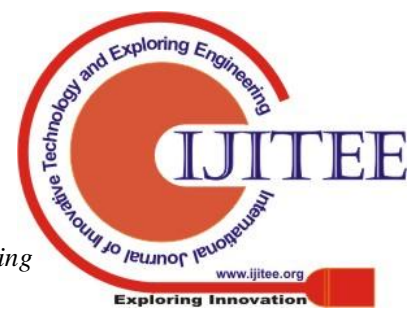


* Thus the NiW thin layer enhances the surface properties of MS, thus decreasing its wear rate or increasing wear resistance and also decreases the coefficient of friction and frictional force

* Hence the application of NiW thin layer on MS material improves the failure time of the material due to wear which plays a huge role in all mechanical aspects.

\section{ACKNOWLEDGEMENT}

The authors would like to express their hearty thanks to the Management of Kumaraguru College of Technology, Coimbatore - 49, Tamilnadu, India for providing financial support to carry out this research work.

\section{REFERENCES}

1. A.P.I Popoola, O.S.I Fayomi and O.M Popoola. Int. J. Electrochem. Sci., 7 (2012) 4898 - 4917.

2. Mahmud Abdulmalik Abdulrahaman et al 2017 Adv. Nat. Sci: Nanosci. Nanotechnol. 8015016.

3. Kulka M, Mikolajczak D, Makulu N, Dziarski P and Miklaszewski A 2016 Surf. Coat. Tech. 291293.

4. E. Selva kumar, S. Venkateshwaran, R. Kannan, M. Selvambikai \& A. S. Pradeep " An Electrode Position Of Tungsten Coatings On The Mild Steel: Structural And Its Wear Behaviour." International Journal of Mechanical and Production Engineering Research and Development, 8, no. 7 (2018): 1012-1018.

5. Venkateshwaran S., Selvakumar E., Senthamil selvan P., Selvambikai M., Kannan R., Pradeep A.S. (2019) Corrosion and Magnetic Characterization of Electroplated $\mathrm{NiFe}$ and NiFeW Soft Magnetic Thin Films for MEMS Applications. In: Lakshminarayanan A., Idapalapati S., Vasudevan M. (eds) Advances in Materials and Metallurgy. Lecture Notes in Mechanical Engineering. Springer, Singapore.

6. R Kannan et al 2018 Mater. Res. Express 5046414.

7. Kannan R, Ganesan S, Selvakumari TM (2012) Synthesis and characterization of nanocrystallineNiFeWS thin films in diammonium citrate bath. Digest J Nanomater Biostruct 7(3):1039-1050.

8. R Kannan, S Ganesan, TM Selvakumari " Structural and magnetic properties of electrodeposited $\mathrm{Ni}-\mathrm{Fe}-\mathrm{WS}$ thin films." Optoelectron Adv Mat, 6, no. 3-4, (2012): 383- 388.

9. O.S. Fayomi, V.R. Tau, A.P.I. Popoola, B.M. Durodola, O.O. Ajayi, C.A. Loto, and O.A. Inegbenebor,. J. of Mat. and Env. Sci., 3, (2011) 271.

10. B.K. Prasad, and O.P. Modi, Trans. of Nonfer. Mat. Sci. China, 19: (2008) 277.

11. Qin, Liyuan, Jiying Xu, Jianshe Lian, Zhonghao Jiang, and Qing Jiang. "A novel electrodeposited nanostructured $\mathrm{Ni}$ coating with grain size gradient distribution." Surface and Coatings Technology 203, no. 1-2 (2008): 142-147.

12. SadanandaRashmiLijuEliasAmparChitharanjan Hegde. Multilayered $\mathrm{Zn}-\mathrm{Ni}$ alloy coatings for better corrosion protection of mild steel" Engineering Science and Technology, an International Journal Volume 20, Issue 3, June 2017, Pages 1227-1232.

13. Kato, Koji. "Wear in relation to friction-a review." Wear 241, no. 2 (2000): 151-157.

14. rasad, D.S., Ebenezer, N.S. \& Shoba, C. Trans Indian Inst Met (2017) 70: 2601. https://doi.org/10.1007/s 12666-017-1121-y

15. C.S.Ramesh and S.K.Seshadri" Tribological characteristics of nickel based composite coatings, Wear Volume 255, Issues 712, August-September 2003, Pages 893-902. https://doi.org/10.1016/S0043-1648(03)00080-2

16. M. Surender, B. Basu and R. Balasubramaniam. " Wear characterization of electrodeposited $\mathrm{Ni}-\mathrm{WC}$ composite coatings." Tribology International Volume 37, Issue 9, September 2004, Pages 743-749. 